\title{
Development and Validation of a Knowledge Test for Health Professionals Regarding Lifestyle Modification
}

\author{
Whadi-ah Talip, BSc Hons, Nelia P. Steyn, PhD, Marianne Visser, MPH MSc, \\ Karen E. Charlton, MPH, and Norman Temple, PhD \\ From the Nutrition and Dietetics Unit, Department of Medicine, University of Cape Town, \\ Cape Town, South Africa; the Chronic Diseases of Lifestyle Program, Medical Research \\ Council, Tygerberg, South Africa; and the Centre for Science, Athabasca University, \\ Athabasca, Alberta, Canada
}

\begin{abstract}
OBJECTIVE: We wanted to develop and validate a test that assesses the knowledge and practices of health professionals (HPs) with regard to the role of nutrition, physical activity, and smoking cessation (lifestyle modification) in chronic diseases of lifestyle.

METHODS: A descriptive cross-sectional validation study was carried out. The validation design consisted of two phases, namely 1) test planning and development and 2) test evaluation. The study sample consisted of five groups of HPs: dietitians, dietetic interns, general practitioners, medical students, and nurses. The overall response rate was $58 \%$, resulting in a sample size of 186 participants. A test was designed to evaluate the knowledge and practices of HPs. The test was first evaluated by an expert group to ensure content, construct, and face validity. Thereafter, the questionnaire was tested on five groups of HPs to test for criterion validity. Internal consistency was evaluated by Cronbach's $\alpha$.

RESULTS: An expert panel ensured content, construct, and face validity of the test. Groups with the most training and exposure to nutrition (dietitians and dietetic interns) had the highest group mean score, ranging from $61 \%$ to $88 \%$, whereas those with limited nutrition training (general practitioners, medical students, and nurses) had significantly lower scores, ranging from $26 \%$ to $80 \%$. This result demonstrated criterion validity. Internal consistency of the overall test demonstrated a Cronbach's $\alpha$ of 0.99. Most HPs identified the mass media as their main source of information on lifestyle modification. These HPs also identified lack of time, lack of patient compliance, and lack of knowledge as barriers that prevent them from providing counseling on lifestyle modification.

CONCLUSIONS: The results of this study showed that this test instrument identifies groups of health professionals with adequate training (knowledge) in lifestyle modification and those who require further training (knowledge). Nutrition 2003;19:760-766. CElsevier Inc. 2003
\end{abstract}

KEY WORDS: dietary survey, knowledge questionnaire, health professionals, public health

\section{INTRODUCTION}

The phenomenon of urbanization in South Africa has resulted in major changes in the lifestyles of people who have migrated from rural to urban areas, including their dietary, physical activity, and smoking habits. In general, "traditional diets" (high fiber and low fat) have been replaced by "Western diets" (low fiber, high fat, and sugar). This process has been termed the nutrition transition. ${ }^{1,2}$ In addition, levels of physical activity have tended to decrease and smoking (nicotine) has tended to increase.

As can be expected, these changes are reflected in the mortality patterns in the country. Formerly, most deaths occurred as a result of infectious diseases. However, due to increases in the prevalence of chronic diseases of lifestyle (CDOLs), such as hypertension, type 2 diabetes mellitus, coronary heart disease, and obesity, this is no longer so. ${ }^{3}$ By 1996 CDOLs were reported to be the cause of $40 \%$ of deaths in the economically active age group of 24 to $64 \mathrm{y} .{ }^{4}$

Correspondence to: Nelia P. Steyn, PhD, Chronic Diseases of Lifestyle Unit, Medical Research Council, PO Box 19070, Tygerberg, South Africa. E-mail: nelia.steyn@mrc.ac.za
The 1998 South African Demographic and Health Survey (SADHS) recorded the self-reported prevalence of CDOLs. Overall, these results indicated prevalences of $8 \%$ and $19 \%$ for hypertension, $3 \%$ and $6 \%$ for coronary heart disease, $2.4 \%$ and $4 \%$ for type 2 diabetes, and $9 \%$ and $30 \%$ for obesity in men and women, respectively. In addition, the SADHS reported prevalences of $42 \%$ and $11 \%$ for smoking in men and women, respectively. ${ }^{5}$ These findings indicate an urgent need to educate the population about a healthy lifestyle, including a low-fat, high-fiber diet, increased physical activity, and reduced tobacco consumption.

Counseling on lifestyle modification, including diet, physical activity, and smoking cessation, can be effective in the prevention and management of CDOLs. ${ }^{1,6-9}$ However, by July 2001, there were only 1285 dietitians and 400 biokineticists registered with the Health Professions Council of South Africa, with fewer than 500 employed in the public health sector. ${ }^{10}$ Basically there are too few trained people to council the population. Patients are therefore more likely to be in contact with general health professionals (HPs), such as doctors and nurses at community health centers, and less likely to be in contact with professionals trained in nutrition or physical activity.

Nevertheless, patients perceive the general HPs (general practitioners [GPs] and nurses) to be reliable sources of dietary 
information. ${ }^{11-16}$ Recommendations and counseling by GPs have also been cited as significant reasons for increasing physical activity levels and smoking cessation. ${ }^{15,16}$ Therefore, we propose that these HPs could serve as lifestyle modification educators within the community.

However, GPs and nurses have limited training in specialized areas such as nutrition and physical activity. ${ }^{14}$ An evaluation instrument that measures knowledge and practices of HPs with regard to the role of lifestyle modification in the prevention and management of CDOLs will help to identify those who require further training. In addition, identifying the barriers to counseling about these issues will detect specific target areas for interventions to increase counseling by HPs. This article describes the development and validation of such an instrument, as such a validated tool did not exist.

\section{MATERIALS AND METHODS}

\section{Study Design}

A descriptive cross-sectional validation study was carried out. The validation design consisted of two phases. Phase 1 included the process of test planning of an instrument to measure lifestyle knowledge and practices, and phase 2 involved test evaluation. The purpose of the validation study was to establish whether the test instrument could distinguish groups of HPs with adequate lifestyle modification knowledge from those who require further training.

\section{Test Planning and Development}

Test planning and development procedures followed those outlined by Dwyer et al., ${ }^{17}$ Byrd-Bredbenner, ${ }^{18}$ and Lackey et al. ${ }^{19}$ Test planning involved identifying a framework for the content that the test instrument would cover. ${ }^{17}$ The knowledge and practices of HPs regarding the role of lifestyle modification (nutrition, physical activity, and smoking cessation) in the prevention and management of CDOLs were chosen as the framework for the test construction.

A panel, comprising seven experts in the fields of nutrition, physical activity, and smoking cessation, was established to determine which concepts the test instrument should cover (Appendix). Test items were constructed with input from these experts and from the literature, South African nutrition guidelines, and position papers as resource material. ${ }^{20-24}$ Initially 85 knowledge test items and 24 scaled practice items were constructed. Members of the expert panel were consulted to address the relative importance of the designed test items, thus further ensuring content validity. Test items then were revised accordingly.

The final validation test comprised 157 test items: six were demographic, 93 were related to knowledge (40 avoid/allowed, 46 true/false, and 7 multiple choice), and 58 were related to practices (7 multiple choice, 19 yes/no, and 32 scaled). Each knowledge item also carried a don't know response. Responses to knowledge items scored 1 point if correct or 0 point if incorrect. Thus, the possible scores ranged from 0 to 93 . Data from practice items were summarized on a qualitative ranking.

The test was divided into six sections. Section A included demographic items related to age, sex, educational background, and current position of employment. It also addressed the respondents' perceived knowledge, confidence in counseling, and barriers that prevent counseling and identified their main source of information on lifestyle modification. Sections B, C, and D comprised items that were designed to assess the respondents' knowledge and practices regarding the role of nutrition, physical activity, and smoking cessation in the management of CDOLs. Each section was based on a case study related to a particular CDOL and its associated complications.

\section{Example of a Case Study (Section B)}

Mr Solomons, a 46-y-old man from Manenberg presents with chest pains. He is currently unemployed. He leads a sedentary lifestyle and consumes four beers and two tots of whisky every night. He also smokes 15 cigarettes a day. His cholesterol level is $7.3 \mathrm{mM} / \mathrm{L}$ (normal $<5 \mathrm{mM} / \mathrm{L}$ ). He is referred to you for advice regarding lifestyle modification.

Section B included items on the dietary management of coronary heart disease and practices regarding smoking cessation counseling. Section $\mathrm{C}$ comprised items relating to the dietary management of hypertension and obesity and items regarding physical activity. Section D included items that focused on the dietary and medical management of type 2 diabetes. Section $E$ focused on general nutrition knowledge items related to all chronic diseases. Section $\mathrm{F}$ identified the practices that HPs undertake during an initial consultation with patients with chronic disease and the frequency of access to and consultation with registered experts in the field of nutrition, physical activity, and smoking cessation.

The test also included a section for feedback from respondents regarding the content, design, and layout of the test. These consisted of three open-ended items. The responses to these items were taken into consideration in the development of the final test, thereby further ensuring face and construct validity. In addition, respondents were asked to record the times at which they started and completed the test to estimate respondents' average completion time.

\section{Test Evaluation and Validation Design}

To establish criterion validity, the test was administered to different groups of HPs. These groups were identified and selected on the basis of their training, education, and exposure to nutrition and lifestyle modification. ${ }^{17}$ Five groups of HPs were selected: registered dietitians, dietetic interns, GPs, registered nurses, and medical students.

By necessity (mainly due to different working conditions) testing procedures and test items relating to practices differed slightly between and within groups. The dietetic interns (final-year students at the University of Cape Town, University of the Western Cape, and Stellenbosch University) and nurses at Cape Technikon (registered nurses attending a course in public health) generally completed the test under supervised testing conditions. Nurses at community health centers performed the test outside classroom due to time and physical space constraints. The dietitians completed the test during a break at a symposium on continuing professional development; tests were returned the same day. GPs also were addressed at a course on continuing professional development but opted to return the completed tests by mail. Thus, with the exception of the GPs, test conditions were similar.

\section{Statistical Analyses}

Data were analyzed with Statistica 5.5. The data collected did not display the Gaussian curve of normality; therefore, non-parametric analyses were used, specifically the Kruskal-Wallis analysis of variance by sum of ranks, thus allowing for the determination of criterion validity.

The split-half reliability of the test was calculated with Cronbach's $\alpha$, a test commonly used to determine the internal consistency and reliability of a test. ${ }^{25}$ Spearman's correlation for ranked data was used to determine the degree of association between perceived knowledge rating and actual knowledge score. Chisquare tests were used to determine the relation between categoric data, e.g., how practices differed between groups of HPs. 
TABLE I.

SAMPLE SIZE AND RESPONSE RATE OF PARTICIPANTS

\begin{tabular}{lrcr}
\hline Group & $\begin{array}{c}\text { Sample } \\
\text { size }\end{array}$ & $\begin{array}{c}\text { Returned } \\
\text { questionnaires }\end{array}$ & $\begin{array}{c}\text { Response } \\
\text { rate (\%) }\end{array}$ \\
\hline Dietitians & 100 & 60 & 60 \\
Dietetic interns & 37 & 37 & 100 \\
General practitioners & 50 & 14 & 28 \\
Medical students & 50 & 23 & 46 \\
Nurses at CHC & 50 & 26 & 52 \\
Nurses at Ctech & 35 & 26 & 74 \\
All groups & 322 & 186 & 58 \\
\hline
\end{tabular}

CHC, Community Health Centres; Ctech, Cape Technikon

\section{Ethical Approval}

The study was approved by the Ethics Committee of the University of Cape Town. Informed consent was obtained from participants who were able to participate by choice and without coercion after the purpose of the study had been explained to them.

\section{RESULTS}

A total of 322 subjects were surveyed, 186 of whom completed and returned the test, giving an overall response rate of 58\% (Table I). However, the response rates for the different groups varied from $28 \%$ to $100 \%$. This variation largely reflected the different methods of data collection used for each group. Test administration under supervised conditions delivered a better response than did tests returned by mail. GPs had a response rate of only $28 \%$; as a consequence, their results needed to be interpreted cautiously.

The data collected were analyzed in two separate sections, namely data relating to knowledge and practices of respondents with regard to the role of lifestyle modification in CDOLs.

\section{Knowledge}

Table II displays the mean test scores per section for each group. Dietitians had the highest mean score followed by dietetic interns and medical practitioners. Medical students and nurses had the lowest mean scores. Using the Kruskal-Wallis analysis of variance by sum of ranks test, significant differences $(P=0.03)$ between groups in all sections were calculated. This is an indication of criterion validity.
Based on the combined test results for the nurses, GPs, and medical students, the split-half reliability of the test per section was calculated. An $\alpha$ value of 0.89 was reported for section B, and $\alpha$ values of 0.99 were reported for sections C, D, and E and for the overall test.

To determine the degree of difficulty of the individual test items, item analysis was undertaken. Overall, 34 of the 93 items had a high difficulty index ( 0.90 to 1.00$)$, indicating that $90 \%$ or more of respondents correctly answered these 34 items. Among dietitians and interns, 59 and 51 items, respectively, had a high difficulty index (more than $90 \%$ answered correctly). This decreased to 34, 26, and 13 items for GPs, medical students, and nurses, respectively. This showed that test items were easier for persons with training in nutrition than for persons with limited training, thus further ensuring criterion validity. Very easy or very difficult items do not discriminate between groups who have different levels of expertise in an area. ${ }^{17}$ For this reason, 12 items with difficulty indices above 0.9 and one item with a difficulty index of 0.34 were eliminated. There were, however, six items that reflected difficulty indices of 0.30 or less. These items were retained because they provided valuable information regarding specific areas of nutrition that require further attention. These areas included misconceptions regarding food sources of cholesterol, fad diets for weight loss, and dietary management of type 2 diabetes.

\section{Practices}

MAIN SOURCES OF INFORMATION. Dietitians (41\%) and GPs $(55 \%)$ reported that continuing medical education (CME) courses were the most frequently accessed source of nutrition information, followed by scientific journals. In contrast, dietetic interns $(43 \%)$ indicated textbooks to be their main source of nutrition information, and most medical students (74\%) and nurses (38\%) relied on information supplied by the mass media.

Most dietitians, dietetic interns, medical students, and nurses indicated that they received most of their information regarding physical activity and smoking cessation from the media $(55 \%$, $64 \%, 82 \%$, and $58 \%$, respectively). GPs, however, identified CME courses as their main source of information about physical activity and smoking cessation.

There was a significant difference $(P<0.05)$ between groups for all sources of information on nutrition and smoking cessation. However, no significant difference $(P=0.67)$ was found between groups for information sources on physical activity.

CONFIDENCE IN COUNSELING. Most respondents in all groups indicated that they were confident in their ability to provide counseling on nutrition (86\%), physical activity (68\%), and smok-

TABLE II

MEAN KNOWLEDGE TEST SCORES OF ALL RESPONDENTS PER SECTION OF THE TEST*

Test scores per section (total points)

\begin{tabular}{lccrr}
\cline { 2 - 5 } Group $(n) \dagger$ & CHD (23) & Hypertension (3) & Diabetes (28) & General (9) \\
\hline Dietitians (60) & $20.7 \pm 1.8$ & $29.3 \pm 2.3$ & $22.0 \pm 2.0$ & $8.2 \pm 0.9$ \\
Dietetic interns (37) & $19.6 \pm 1.8$ & $29.2 \pm 2.1$ & $21.7 \pm 1.9$ & $8.5 \pm 1.0$ \\
General practitioners (14) & $18.3 \pm 2.1$ & $23.6 \pm 5.1$ & $20.0 \pm 3.0$ & $78.1 \pm 4.2$ \\
Medical students (23) & $15.4 \pm 2.1$ & $25.0 \pm 3.7$ & $17.3 \pm 3.1$ & $6.4 \pm 1.6$ \\
Nurses (49) & $15.7 \pm 3.0$ & $22.9 \pm 4.7$ & $18.0 \pm 3.2$ & $5.3 \pm 1.7$ \\
\hline
\end{tabular}

* Values are mean \pm standard deviation.

$\dagger P=0.031$, Kruskal-Wallis.

CHD, coronary heart disease 
TABLE III.

BARRIERS TO COUNSELING IDENTIFIED BY GENERAL PRACTITIONERS AND NURSES

\begin{tabular}{|c|c|c|c|c|c|c|}
\hline \multirow[b]{2}{*}{ Barrier } & \multicolumn{2}{|c|}{ Nutrition } & \multicolumn{2}{|c|}{ Physical activity } & \multicolumn{2}{|c|}{ Smoking cessation } \\
\hline & GPs $(\%)$ & Nurses $(\%)$ & GPs $(\%)$ & Nurses $(\%)$ & GPs $(\%)$ & Nurses $(\%)$ \\
\hline Lack of time & 92 & 79 & 100 & 78 & 69 & 64 \\
\hline Lack of financial reimbursement & 11 & 43 & 11 & 33 & 11 & 33 \\
\hline Lack of knowledge & 60 & 23 & 33 & 40 & 22 & 47 \\
\hline Lack of patient compliance & 33 & 58 & 33 & 54 & 56 & 65 \\
\hline
\end{tabular}

GPs, general practitioners

ing cessation $(74 \%)$ to their patients. However, the data suggested that dietitians and dietetic interns were more confident in their ability to provide counseling on nutrition $(100 \%$ and $100 \%$, respectively) than on physical activity (64\% and 65\%) or smoking cessation (71\% and $61 \%$ ). GPs and medical students appeared to be more confident in their ability to provide counseling on smoking cessation ( $86 \%$ and $91 \%$, respectively) than on physical activity $(64 \%$ and $61 \%)$ or nutrition counseling (57\% and $52 \%)$.

BARRIERS PREVENTING COUNSELING. As expected, most dietitians $(61 \%$ to $95 \%)$ stated that they had no barriers to nutrition counseling. Similar results were obtained for dietitians regarding physical activity and smoking cessation counseling. Table III presents barriers to counseling as identified by GPs and nurses. A lack of time was the barrier most frequently identified, followed by a lack of patient compliance. GPs also indicated that a lack of knowledge was a barrier preventing nutrition counseling.

PERCEIVED EFFECTIVENESS OF COUNSELING. As a measure of identifying how HPs perceive the effectiveness of lifestyle modification counseling, respondents were asked to estimate the frequency with which patients would follow the advice that they supplied regarding lifestyle modification (Table IV). Of the respondents, $65 \%$ indicated that counseling on nutrition often would be effective, $50 \%$ indicated this for physical activity counseling, whereas only $24 \%$ indicated this for smoking cessation counseling.

PERCEIVED KNOWLEDGE RATING VERSUS ACTUAL KNOWLEDGE SCORE. Most dietitians (57\%), dietetic interns $(62 \%)$, and nurses $(70 \%)$ rated their nutrition knowledge as good, whereas $50 \%$ of GPs and $61 \%$ of medical students rated their knowledge as mediocre.

We also examined the respondents' perceived knowledge regarding nutrition and physical activity in relation to their actual knowledge scores and the correlation within each group. A significant correlation $(P<0.05)$ was seen in all groups regarding perceived knowledge with actual knowledge scores. With regard to nutrition, the results indicated weak negative correlations for dietitians, dietetic interns, and GPs and a weak positive correlation for nurses and medical students. Similar results were observed for physical activity, but no significant differences $(P=0.40)$ between groups were found.

PRACTICES IMPLEMENTED ON INITIAL OBSERVATION OF A PATIENT WITH CDOL. Table V summarizes the practices implemented by various HPs at the initial visit of a patient with a CDOL. Most dietitians and nurses indicated that they have access to equipment. In addition, all respondents indicated that they frequently measure body weight. Dietitians were consistent in measuring height and calculating body mass index, whereas GPs and nurses reported seldom doing so. Most dietitians also reported taking a diet history and inquiring about activity levels and smoking habits. Similar results were observed for nurses, but to a lesser extent. The results indicated that GPs and nurses are more likely to inquire about smoking habits than about dietary habits.

ACCESS TO AND CONSULTATION WITH EXPERTS IN LIFESTYLE MODIFICATION. The results indicated that most GPs and nurses practicing at a primary health care level do not have access to, or consult with, experts in physical activity (79\% and $64 \%$, respectively) or smoking cessation (84\% and $66 \%$ ).

TABLE IV.

PERCEIVED EFFECTIVENESS OF LIFESTYLE MODIFICATION COUNSELING BY HEALTH PROFESSIONALS

\begin{tabular}{|c|c|c|c|c|c|c|c|c|c|}
\hline & $\begin{array}{c}\text { Often } \\
(\%)\end{array}$ & $\begin{array}{c}\text { Sometimes } \\
(\%)\end{array}$ & $\begin{array}{l}\text { Seldom } \\
(\%)\end{array}$ & $\begin{array}{c}\text { Often } \\
(\%)\end{array}$ & $\begin{array}{c}\text { Sometimes } \\
(\%)\end{array}$ & $\begin{array}{c}\text { Seldom } \\
(\%)\end{array}$ & $\begin{array}{c}\text { Often } \\
(\%)\end{array}$ & $\begin{array}{c}\text { Sometimes } \\
(\%)\end{array}$ & $\begin{array}{c}\text { Seldom } \\
(\%)\end{array}$ \\
\hline Dietitians & 87 & 13 & 0 & 69 & 29 & 2 & 28 & 69 & 3 \\
\hline Dietetic interns & 70 & 27 & 3 & 51 & 48 & 3 & 24 & 43 & 32 \\
\hline Nurses & 60 & 36 & 4 & 47 & 47 & 6 & 25 & 43 & 31 \\
\hline All groups & 65 & 31 & 4 & 50 & 43 & 8 & 24 & 51 & 25 \\
\hline
\end{tabular}


TABLE V.

FREQUENCY OF PRACTICES IMPLEMENTED BY HEALTH PROFESSIONALS ON INITIAL OBSERVATION OF A PATIENT WITH A CHRONIC DISEASE OF LIFESTYLE

\begin{tabular}{|c|c|c|c|c|c|c|c|c|c|}
\hline & \multicolumn{3}{|c|}{ Dietitians } & \multicolumn{3}{|c|}{ General practitioners } & \multicolumn{3}{|c|}{ Nurses } \\
\hline & $\begin{array}{l}\text { Often } \\
(\%)\end{array}$ & $\begin{array}{c}\text { Sometimes } \\
(\%)\end{array}$ & $\begin{array}{l}\text { Seldom } \\
(\%)\end{array}$ & $\begin{array}{l}\text { Often } \\
(\%)\end{array}$ & $\begin{array}{c}\text { Sometime } \\
(\%)\end{array}$ & $\begin{array}{l}\text { Seldom } \\
(\%)\end{array}$ & $\begin{array}{c}\text { Often } \\
(\%)\end{array}$ & $\begin{array}{c}\text { Sometimes } \\
(\%)\end{array}$ & $\begin{array}{c}\text { Seldom } \\
(\%)\end{array}$ \\
\hline Access to equipment & 91 & 7 & 2 & 46 & 46 & 8 & 75 & 17 & 8 \\
\hline Measure body weight & 93 & 4 & 4 & 100 & 0 & 0 & 71 & 19 & 10 \\
\hline Measure height & 89 & 4 & 7 & 38 & 31 & 31 & 35 & 33 & 33 \\
\hline Calculate BMI & 93 & 2 & 5 & 17 & 33 & 50 & 9 & 32 & 60 \\
\hline Take a diet history & 100 & 0 & 0 & 23 & 23 & 54 & 52 & 27 & 21 \\
\hline Enquire about an activity level & 98 & 2 & 0 & 38 & 46 & 15 & 57 & 31 & 12 \\
\hline Enquire about smoking habits & 80 & 16 & 4 & 54 & 38 & 8 & 67 & 20 & 12 \\
\hline
\end{tabular}

BMI, body mass index

Respondents also appeared to have limited knowledge of smoking cessation services available in the community to which they could refer patients. Only $9 \%$ indicated that they are aware of some services.

\section{DISCUSSION}

It has been proposed that HPs, such as physicians, nurses, and pharmacists, be used as lifestyle modification educators, because studies have demonstrated that counseling by these HPs are effective in inducing lifestyle modification. ${ }^{26-28}$

This study evaluated the knowledge and practices of HPs in various health settings. A previous survey conducted in Cape Town, among GPs at community health centers and interns at Groote Schuur Hospital, showed that nutritional knowledge regarding CDOLs was poor. ${ }^{14}$ This is in accordance with studies in other countries. ${ }^{29-34}$

Therefore, we wanted to develop, validate, and carry out a test that would measure knowledge and practices of HPs regarding the role of lifestyle modification in the prevention and management of CDOLs, thereby identifying those HPs who require further training in this field. In addition, identifying the barriers to counseling on these issues might show target areas for interventions to increase counseling by HPs.

The procedures outlined in MATERIALS AND METHODS, including the consultation with expert groups and the compilation of scientific literature regarding lifestyle modification on CDOL, ensured the content validity of the test.

Face and construct validities were achieved by the provision of a feedback section at the end of the test instrument. The respondents were asked to comment on the language, items, format, and construct of the test. Minimal adjustments, such as the rephrasing of test items, were then made.

After analysis of test results, groups known to have the most training and exposure to nutrition (dietitians and dietetic interns) had the highest group mean score, ranging from $61 \%$ to $88 \%$, and those with limited nutrition training (GPs, medical students, and nurses) had significantly lower scores, ranging from $26 \%$ to $80 \%$. This demonstrated criterion validity. However, due to differences in testing procedures, comparisons can be made only at a broad level. ${ }^{17}$ Similar results were reported in studies conducted in South Africa, Canada, and United States. ${ }^{14,30,35}$

The evaluation of item difficulty showed that test items are easier for persons with training in nutrition than for persons with limited training, thus further ensuring criterion validity. Very easy or very difficult items do not discriminate between groups who have different levels of expertise in an area. ${ }^{17}$ For this reason, items with difficulty indices above 0.9 and below 0.34 were eliminated.

The present results indicated that nurses and medical students most frequently obtain nutrition information from the mass media. In addition, all HPs appeared to acquire information regarding physical activity and smoking cessation from the media. Previous studies have shown similar results. ${ }^{30,32,35}$

It has been reported that GPs lack confidence in their nutrition counseling skills. ${ }^{11}$ However, the present results showed that most respondents in all professional groups were confident in providing lifestyle modification counseling.

Major barriers to counseling identified in this study included a lack of time and a lack of patient compliance. This observation reaffirmed results reported in previous studies. ${ }^{14,27,36-39}$ It is important to note that, although GPs had a higher mean knowledge score than medical students and nurses, they were the only group of HPs who reported a lack of knowledge as a barrier to providing counseling on nutrition. In addition, correlations between perceived knowledge and actual knowledge scores showed weak negative associations for GPs. This result implied that GPs tend to underrate their nutrition knowledge. Similar results were obtained for dietitians and dietetic students. However, these results could be attributed to the fact that the scope of their nutrition knowledge was more detailed than the basic principles that the test encompassed. Conversely, correlations for nurses and medical students showed a weak positive correlation, indicating that their perceived knowledge is reflective of their actual knowledge on nutrition.

The results of this study indicated that most HPs offer smoking cessation counseling to their patients. It is important to note that all respondents were not familiar with the term nicotine replacement therapy, implying that there are groups of HPs that require further education on this subject. In addition, the results showed that HPs have limited knowledge of smoking cessation services within the community. Thus, information regarding these services should be made available to all HPs.

As illustrated by the Expanded Food and Nutrition Education Program, health promotion and education have been shown to be a cost-effective means of preventing diet-related CDOLs. ${ }^{40,41}$ It also has been shown that smoking cessation interventions delivered through the National Health Service are an extremely costeffective way of managing CDOLs. ${ }^{28}$ Moreover, studies have shown that health promotion campaigns targeted at specific "highrisk groups" may be more cost effective than those aimed at the general population. ${ }^{42}$

In summary, the final validated test instrument had nearly the same contents as the validation test. However, through the process 
APPENDIX.

CONCEPTUAL FRAMEWORK FOR THE NUTRITION AND LIFESTYLE KNOWLEDGE TEST

\begin{tabular}{|c|c|c|c|c|}
\hline & Coronary heart disease & Hypertension & Diabetes & Obesity \\
\hline \multicolumn{5}{|l|}{ Nutrition concepts } \\
\hline \multirow{8}{*}{$\begin{array}{l}\text { Foods or nutrients that have } \\
\text { a causative effect, i.e., } \\
\text { promote the development } \\
\text { of the disease }\end{array}$} & Fats & Alcohol & Fats & Fats \\
\hline & Difference between & SFA & Total energy & Total energy \\
\hline & PUFA, MUFA, SFA, & Animal products & Complex CHO & Alcohol \\
\hline & and TFA & High salt content & High GI foods & Refined $\mathrm{CHO}$ \\
\hline & Cholesterol & & & \\
\hline & LDL-C, HDL-C & & & \\
\hline & $\omega-3, \omega-6$ & & & \\
\hline & $\begin{array}{l}\text { Total fat versus types } \\
\text { of fat }\end{array}$ & & & \\
\hline \multirow{4}{*}{$\begin{array}{l}\text { Foods or nutrients that have } \\
\text { a preventative effect on } \\
\text { the development of the } \\
\text { disease }\end{array}$} & Fiber & Fruit & Fiber & Fruit \\
\hline & Alcohol & Vegetables & Pulses & Vegetables \\
\hline & Antioxidants & High potassium & & \\
\hline & Plants sterols & Dairy & & \\
\hline \multirow[t]{3}{*}{ Practices and habits } & Food labeling, i.e., first 3 & Seasoning substitution for & Meal planning & Meal plan \\
\hline & ingredients on the list & salt & Snacks & Street foods \\
\hline & Cooking habits & No salt & & Fruit juice versus soft drink \\
\hline \multirow[t]{6}{*}{ Management criteria } & Blood lipid control & B Pressure control & Blood glucose control & BMI \\
\hline & Cholesterol control & When to control BP by & When to control glucose & Weight loss/wk \\
\hline & $\begin{array}{l}\text { When to control } \\
\text { cholesterol levels by }\end{array}$ & $\begin{array}{l}\text { diet alone and when to } \\
\text { prescribe drugs }\end{array}$ & $\begin{array}{l}\text { levels by diet alone and } \\
\text { when to prescribe }\end{array}$ & \\
\hline & diet alone and when to & Weight loss & drugs & \\
\hline & prescribe drugs & & GI control & \\
\hline & Weight loss & & Weight loss & \\
\hline \multicolumn{5}{|l|}{ PA concepts } \\
\hline \multirow{4}{*}{$\begin{array}{l}\text { Exercise dose response for } \\
\text { primary prevention of } \\
\text { CDOL }\end{array}$} & \multirow{4}{*}{\multicolumn{4}{|c|}{$\begin{array}{l}\text { Regular PA results in at least a } 1.5 \text {-fold decreased risk for CHD, HPT, NIDDM, and obesity } \\
30 \text { min of moderate to vigorous PA on most days (accumulative) } \\
\text { Expected re-assessment not }>6 \mathrm{wk} \text {, preferably } 8-12 \mathrm{wk} \\
\text { Strength training and flexibility } 2-3 \text { times a week: activities to increase muscle strength and endurance }\end{array}$}} \\
\hline & & & & \\
\hline & & & & \\
\hline & & & & \\
\hline \multirow{4}{*}{$\begin{array}{l}\text { Mechanisms for } \\
\text { preventative effects of } \\
\text { exercise on CDOL }\end{array}$} & Decreases LDL, BP & Acute lowering of BP & Increases glucose & Increases EE \\
\hline & $\begin{array}{l}\text { Increases HDL, } \\
\text { myocardial perfusion, }\end{array}$ & Increases contractility & $\begin{array}{l}\text { tolerance, } \mathrm{HbA1c}, \\
\text { insulin sensitivity }\end{array}$ & $\begin{array}{l}\text { Decreases waist } \\
\text { circumferences }\end{array}$ \\
\hline & exercise tolerance & & Decreases weight, lipids & Decrease comorbidities \\
\hline & & & & Increases adherence \\
\hline Practices and habits & & $\begin{array}{l}\text { Avoid exercise with arms } \\
\text { overhead for extended } \\
\text { periods }\end{array}$ & $\begin{array}{l}\text { Avoid excessive increases } \\
\text { in BP (risk of } \\
\text { microvascular damage) }\end{array}$ & \\
\hline \multirow[t]{2}{*}{ Management criteria } & \multicolumn{4}{|l|}{ "Readiness for change" } \\
\hline & \multicolumn{4}{|c|}{$\begin{array}{l}\text { Pre-exercise risk screening }(>2 \text { risk factors require stress ECG or pre-exercise medical examination: reduced activity, } \\
\text { smoking, }>50 \text { y for women, }>40 \text { y for men, BP }>140 / 90 \text {, type } 2 \text { DM, family history of heart problems, known } \\
\text { diseases or abnormal ECG) }\end{array}$} \\
\hline
\end{tabular}

BMI, body mass index; CDOL, chronic diseases of lifestyle; CHD, coronary heart disease; CHO, carbohydrate; DM, diabetes mellitus; ECG, electrocardiogram; GI, glycemic index; HbA1c, hemoglobin A1c; HDL-C, high-density lipoprotein cholesterol; HPT, hypertension; LDL-C, low-density lipoprotein cholesterol; MUFA, monounsaturated fatty acid; NIDDM, non-insulin-dependent diabetes mellitus; PA, physical activity; PUFA, polyunsaturated fatty acid; SFA, saturated fatty acid; TFA, trans fatty acids

of item analysis, the number of test items was reduced from 93 to 80 . Because the test instrument demonstrated a high overall internal consistency, we recommend that the test be used as a tool to distinguish groups of HPs with adequate training in lifestyle modification from those who require further training.

The test is available by request at nelia.steyn@mrc.ac.za.

\section{REFERENCES}

1. Popkin BM. The nutrition transition and obesity in the developing world. J Nutr 2001;131:871S

2. Bourne LT, Steyn K. Rural/urban nutrition-related differentials among adult population groups in South Africa, with special emphasis on the black population. S Afr J Clin Nutr 2000;13:S23
3. Walker AR. Changes in public health in South Africa from 1876. J R Soc Health 2001;2:85

4. Medical Research Council. Chronic diseases of lifestyle. S Afr Med J 1996;86: 312

5. Department of Health, Republic of South Africa. South Africa demographic and health survey 1998. Full report. Pretoria: Government Printers, 2002

6. Knowler WC, Barrett-Connor E, Fowler SE, et al. Reduction in the incidence of type 2 diabetes with lifestyle modification or metformin. N Engl J Med 2002; $346: 393$

7. Lichtenstein AH, Ausman LM, Jalbert SM, et al. Efficacy of a therapeutic lifestyle change/step 2 diet in moderately hypercholesterolaemic middle-aged and elderly female and male subjects. J Lipid Res 2002;43:264

8. Tucker KL, Buranapin N. Nutrition and aging in developing countries. J Nutr 2001;131:2417S

9. Solomons NW. Adult nutrition and cities - an international perspective. S Afr J Clin Nutr 2000;13:S13 
10. Health Professionals Council of South Africa. Accessed 15 October 2002. Available at: www.hpcsa.co.za.

11. Kolasa KM. "Images" of nutrition in medical education and primary care. Am J Clin Nutr 2001;73:1006

12. Trinder P. Determination of blood glucose using 4-amino phenazone as oxygen acceptor. J Clin Pathol 1969;22:246

13. World Health Organization Study Group on Diabetes Mellitus. Diabetes mellitus: report of a WHO study group. Technical report 727 . Geneva: World Health Organization, 1985

14. Vengetasamy T, Levitt NS, Visser ME. The nutritional knowledge, attitudes and practices of general practitioners in the greater Cape Town area. Unpublished report, 2002

15. Improving the treatment of tobacco dependence. BMJ 2000;321:311

16. Harris SS, Caspersen CJ, DeFriese GH, Estes EH, Jr. Physical activity counselling for healthy adults as a primary preventive intervention in the clinical setting. JAMA 1989;261:3590

17. Dwyer JT, Stolurow KA, Orr R. A nutrition knowledge test for high school students. J Nutr Educ 1981;13(3):93

18. Byrd-Bredbenner C. A nutrition knowledge test for nutrition educators. J Nutr Educ 1981;13(3):97

19. Lackey CJ, Kolasa KM, Penner KP, Mutch BL. Development of the NKT-a general nutrition knowledge test for teachers. J Nutr Educ 1981;13(3):100

20. Wolmarans P. Dietary guidelines for the treatment of dyslipidaemia in South Africa. A technical report compiled on behalf of the Association for Dietetics in South Africa (ADSA) for the Medical Association of South Africa (MASA), 1999. ADSA, Johannesburg

21. Association for Dietetics in South Africa. Position statement on the dietary management of people with dyslipidaemia. S Afr J Clin Nutr 2000;13:16

22. Association for Dietetics in South Africa. Position statement on the dietary management of people with diabetes mellitus. S Afr J Clin Nutr 1997;9:1233

23. South African Medical Association Dyslipidaemia Nutrition Working Group. Dietary management of dyslipidaemia clinical guidelines. S Afr Med J 2000;90(2)

24. South African Society for the Study of Obesity (SASSO). Draft guidelines on the prevention and management of overweight and obesity in South Africa. Reference document, v10: for expert comment. February 2001

25. Talmage H, Rasher SP. Validity and reliability issues in measurement instrumentation. J Nutr Educ 1981;13(3):83

26. Periera Gray D. Forty-seven minutes a year for the patient. Br J Gen Pract 1998;48:1816
27. Egede LE, Zheng D. Modifiable cardiovascular risk factors in adults with diabetes: prevalence and missed opportunities for physician counseling. Arch Intern Med 2002;162:427

28. Westa R, McNeillb A, Rawe M. Smoking cessation guidelines for health professionals: an update. Thorax 2000;55:987

29. Serra-Majem LL, Calvo JR, Male ML, Ribas L, Lainez P. Population attitudes towards changing dietary habits and reliance on general practitioners in Spain. Eur J Clin Nutr 1999;53:S58

30. Temple NJ. Survey of nutrition knowledge of Canadian physicians. J Am Coll Nutr 1999;18:26

31. Steyn K, Fourie JM, J Shepherd J. Detection and measurement of hypercholesterolaemia in South Africans attending general practitioners on private practicethe cholesterol monitor. S Afr Med J 1998;88:1659

32. Podell RN, Gary LR, Keller K. A profile of clinical nutrition knowledge among physicians and medical students. J Med Educ 1975;50(9):888

33. Buttriss JL. Food and nutrition: attitudes, beliefs and knowledge in the United Kingdom. Am J Clin Nutr 1997;65(suppl):1985S

34. Flynn M, Keithly D, Colwill JM. Nutrition in the education of the family physician. J Am Diet Assoc 1974;65:269

35. Mlodinow SG, Barrett-Connor E. Physicians' and medical students' knowledge of nutrition. Acad Med 1989;64(2):105

36. Scottish Intercollegiate Guidelines Network. SIGN guidelines. Obesity in Scotland. Integrating prevention with weight management. Edinburgh: Scottish Intercollegiate Guidelines Network, 1996

37. Otradovec K, Blake RL, Parker BM. An assessment of the practice of preventative cardiology in an academic health centre. J Fam Pract 1985;21:125

38. Wechsler H, Levine S, Idelson RK, Rohman M, Taylor JO. The physicians role in health promotion - a survey of primary care physicians. N Engl J Med 1983;308:97

39. Anda RF, Remington PL, Sinenko DG, Davis RM. Are physicians advising smokers to quit? The patient's perspective. JAMA 1987;257:1916

40. Rajgopal R, Cox RH, Lambur M, Lewis EC. Cost-benefit analysis indicates the positive economic benefits of the Expanded Food and Nutrition Education Program related to chronic disease prevention. J Nutr Educ 2002;34(1):26

41. Burney J, Haughton B. EFNEP: a nutrition education program that demonstrates cost-benefit. J Am Diet Assoc 2002;102:39

42. Stevens W, Thorogood M, Kayikki S. Cost-effectiveness of a community antismoking campaign targeted at a high risk group in London. Health Promot Internat 2002;17(1):43 